\title{
Impact of a wind climate change on the surge in the southern North Sea
}

\author{
Wim Bijl* \\ National Institute for Coastal and Marine Management, Kortenaerkade 1, 2518 AX Den Haag, The Netherlands
}

\begin{abstract}
The aim of this paper is to gain quantitative insights into the surge-impact of a possible change of the wind climate in the southern part of the North Sea. The approach taken is based upon an initial review of the results of General Circulation Model scenarios for climate change under greenhouse forcing and of their likely effects upon wind climate. Two scenarios of possible wind climate change are formulated. Scenario 1 assumes a northward shift of the entire wind climate system in the

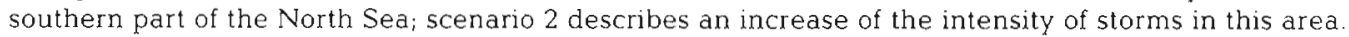
To model these scenarios, the concept of 'parametric storms' is presented, which considers the characteristics of a storm to be conditional upon a limited number of parameters. Applying this concept to the well-known 1953 storm yields promising results. On the basis of this parametric 1953 storm, a large set of storms which are assumed to be consistent with the present (surge generating) wind climate in the southern part of the North Sea is generated. Because these storms do not all have equal chances of occurrence, this set is supplemented by a probability distribution. The future wind climate, which might develop as a result of the 2 wind climate change scenarios, is then modelled by changing this probability distribution and/or some parameters of the storm set. The surge-impact of the 2 modelled scenarios of wind climate change is determined using the Dutch Continental Shelf Model, which describes the depth-averaged tidal flow and storm surges in the North Sea and surrounding areas. For several locations in the southern part of the North Sea, the model output is analyzed and presented in terms of a frequency distribution of storm surge levels. With respect to scenario 1, these simulation results show that a relatively large northward shift of the entire wind climate system in the southern part of the North Sea will only have a small impact on the storm surges in this area. In the case of scenario 2, however, the results show that a relatively small increase of the intensity of depressions in the southern North Sea will result in a relatively large impact on the storm surges in this area.
\end{abstract}

KEY WORDS: Climate change $\cdot$ Scenario study $\cdot$ Downscaling $\cdot$ Storm surge modelling

\section{INTRODUCTION}

For the low lying countries around the North Sea, storms and storm surges are the most damaging climatic features. Possible changes in the position of storm tracks or in the intensity of storms are therefore of great interest. Historical documentation since about $1000 \mathrm{AD}$, as well as instrumental observations over the last century, shows that variations in position of storm tracks and in storm intensities already have occurred (even in the absence of external causes). These varia-

•E-mail: bijl@rikz.rws.minvenw.nl tions seem to be of random nature and are considered to be part of the natural variability of the climate system (Schuurmans 1995a). In view of a possible change of the wind climate, it is, however, no longer obvious that these variations in position of storm tracks or in storm intensities will remain within the same, not clearly specified, bounds of natural variability. In some reports, people already claim that developments are observed which are beyond this range of natural variability (Carter \& Draper 1988, Munich Re 1990, Hogben 1995). The latter, however, still has to be defined. It is therefore important to explore the consequences of a possible exceedance of the bounds of natural variability of the wind climate. 
The present paper focuses on the surge-impact of a possible wind climate change in the southern part of the North Sea. However, because up to now the bounds of natural variability of the present wind climate are not clearly defined, it is not possible to describe this wind climate change unambiguously. Therefore, in Section 2, scenarios of possible wind climate change are formulated which are assumed to reflect the extremes of the most important possible wind climate changes. To model these wind climate change scenarios, use is made of the concept of 'parametric storms' (Section 3). In principle, this concept is similar to the statistical-dynamical approach for the regionalization of climate change scenarios. The first step is to consider the characteristics of a storm to be conditional upon a limited number of parameters (such as storm intensity, storm track, etc.). Next, climate change is represented by changing some of these parameters. On the basis of this concept, the present (surge generating) wind climate in the southern North Sea is modelled in Section 4 using a large set of (parametric) storms. Because these storms do not all have equal chances of occurrence in this area, this set is supplemented by a probability distribution. The subject of Section 5 is the surge-impact of the 2 scenarios of wind climate change. After a description of the numerical model which is used to compute the surge-impact of the large set of storms, the results of these storm surge computations are analyzed and presented in terms of frequency distributions of storm surge levels. These frequency distributions are then used in order to describe the surge-impact of the formulated scenarios of possible wind climate change. Finally, Section 6 contains some discussion and concluding remarks.

\section{ANTHROPOGENIC WIND CLIMATE CHANGE}

\subsection{Greenhouse effect}

The greenhouse effect is a natural process, necessary for the conditions of life on earth. It can be described as a physical process whereby long wave radiation, re-emitted by the warm earth, is partly absorbed and remitted by certain gases in the atmosphere (e.g. carbon dioxide, methane, chlorofluorcarbons, etc.). Since the Industrial Revolution, the concentration of these gases has been increasing (Houghton et al. 1990). This increase of greenhouse gas concentrations has been accompanied by an increase of the global mean surface temperature of the earth at the rate of about $0.5^{\circ} \mathrm{C}$ per century (Stouffer et al. 1994). Up to now, however, it has not been possible to determine whether this observed warming trend is attributable to a man-induced enhanced greenhouse effect associ- ated with increased concentrations of greenhouse gases. At the moment, within the 'scientific community' the discussion on climate change is no longer a discussion on the existence, but merely on the strength and the pattern of the expected change (von Storch et al. 1993). Predictions with respect to the expected increase of the global mean surface temperature show, for example, a wide range of uncertainty: 1.5 to $4.5^{\circ} \mathrm{C}$ in the case of a doubling of the atmospheric carbon dioxide concentration (Houghton et al. 1992). In addition, there is much uncertainty as to the regional pattern of this temperature increase. General Circulation Models (GCMs) play an important role in studies on this topic.

\subsection{General Circulation Models}

In essence, GCMs can be seen as more elaborate versions of the global models which have been employed for weather forecasting. In one respect, however, they differ completely from those numerical weather prediction models, because in these climate models slow and subtle processes are incorporated which for the purpose of normal weather forecasts can. be neglected. Without these processes, a GCM would be unrealistic and might even drift away from the observed means of the climate during numerical integration (Können 1993). The most elaborate GCMs employed at present consist of an atmospheric GCM coupled to an oceanic GCM. The latter describes the structure and dynamics of the ocean. Added to these coupled models are appropriate descriptions of the other components of the climate system like, for example, land surface, ice and the interaction between them. If these coupled GCMs are run for several years with parameters and forcing appropriate to the present climate, the output should bear close resemblance to the observed climate. If parameters representing an increasing amount of the atmospheric carbon dioxide concentration are introduced, these models can be used to predict the resulting climate change.

\subsection{Scenarios of possible wind climate change}

The simulation results of these GCMs with respect to a possible wind climate change are, however, not easy to interpret. Most of these models predict, for example, that in the lower troposphere the largest temperature increase due to an increasing atmospheric carbon dioxide concentration will be in the northern latitudes (Held 1993). This implies a decrease of the (lower tropospheric) pole-to-equator 
temperature gradient in the northern hemisphere, which will have important consequences for the wind climate. One of the most likely effects will be a decrease of the mean wind speeds. These GCMs, however, also indicate that the upper tropospheric poleto-equator temperature gradient in the northern hemisphere will increase, which is exactly opposite to the lower tropospheric situation (Held 1993). In this case, the most likely effect will be an increase of the mean wind speeds. Up to now, it is not clear which of these 2 reverse effects on the development of extratropical cyclones will be dominant. Another point with respect to a possible wind climate change is that the predicted increase of the global mean surface temperature will lead to a poleward retreat of the highly reflective snow and ice cover (Siegmund 1990a, Held 1993). This northward shift of the snow and ice cover will have great influence on atmospheric circulation patterns in the northern hemisphere. The most likely effect will be a slight northward shift of the present weather system in this area (Schuurmans 1995b). The latter is subscribed to in Siegmund (1990b), in which the effect of a doubling of the atmospheric carbon dioxide concentration on the frequency distribution of circulation types over Europe was investigated. The various interpretations of simulation results of GCMs, combined with the fact that the bounds of natural variability of the present wind climate are still not clearly specified (see Section 1), lead to the conclusion that at this moment it is not possible to describe unambiguously the wind-related consequences of a man-induced enhanced greenhouse effect. Therefore, to nevertheless explore the consequences of a possible wind climate change in the southern part of the North Sea, the following 2 scenarios of wind climate change have been formulated (Bijl 1995a), which are assumed to reflect the extremes of the most important possible wind climate changes.

Scenario 1: The possible wind climate change in the southern part of the North Sea will consist of a northward shift of $2^{\circ}$ latitude of the entire wind climate system in this area. This scenario is based on the above-described interpretation of simulation results of GCMs that a poleward retreat of the highly reflective snow and ice cover in the northern hemisphere will lead to a slight northward shift of the wind climate system in this area. A precise quantitative estimate of the size of this northward shift is, however, still not known. In this paper the size of this northward shift has been set at $2^{\circ}$ latitude (about $220 \mathrm{~km}$ ). As described above, this size is quite arbitrary and has in fact been chosen to create an extreme scenario of wind climate change.

Scenario 2: The possible wind climate change in the southern part of the North Sea will consist of an increase in the intensity of storms in this area. This sce- nario is based on the assumption that the impact on the wind climate system of an increase in the upper tropospheric pole-to-equator temperature gradient (as predicted in the northern hemisphere by GCMs) will dominate the impact of the predicted decrease of the temperature gradient in the lower troposphere. Another suggestion for this scenario is the fact that an increased moisture content of the (predicted) warmer air will give rise to a larger release of latent heat in depressions, which enhances storm intensity (Schuurmans 1995b).

\section{PARAMETRIC STORMS}

\subsection{Concept}

In essence, the concept of 'parametric storms' (Ferier et al. 1993) is to approximate the pressure field of a real storm by an artificial (parametric) pressure field. This artificial pressure field is supposed to be asymmetrically elliptic and is described by a specific set of storm parameters. The parameters which are required are summarized below and visualized in Figs. $1 \& 2$.

$\lambda=$ Position of the storm centre in degrees longitude

$\varphi \quad=$ Position of the storm centre in degrees latitude

$a m b=$ Ambient pressure of the storm $(\mathrm{Pa})$

$\delta p=$ Pressure difference between ambient and central pressure $(\mathrm{Pa})$

$\theta=$ Orientation of the east-west axis of the storm in degrees counter-clockwise from east

$\beta=$ Course direction of the storm in degrees counter-clockwise from east

$V \quad=$ Propagation speed of the storm $\left(\mathrm{m} \mathrm{s}^{-1}\right)$

R $\psi n$ = Radius to maximum wind along negative $\psi$-axis $(\mathrm{km})$

$\mathrm{R} \psi \mathrm{p}=$ Radius to maximum wind along positive $\psi$-axis (km)

$\mathrm{R} \xi \mathrm{p}=$ Radius to maximum wind along positive $\xi$-axis (km)

$\mathrm{R} \xi \mathrm{n}=$ Radius to maximum wind along negative $\xi$-axis $(\mathrm{km})$

With respect to the notation of these parameters it has to be mentioned that the $\psi$-axis and $\xi$-axis are locally defined through the centre of the storm, along its principal axes.

The concept also provides the possibility of approximating a sequence of real pressure fields. In that case, a parameter set for both the first and the last pressure field of the sequence is required, whereby the parameters of the intermediate pressure fields are approximated by linear interpolation between those 2 parameter sets 


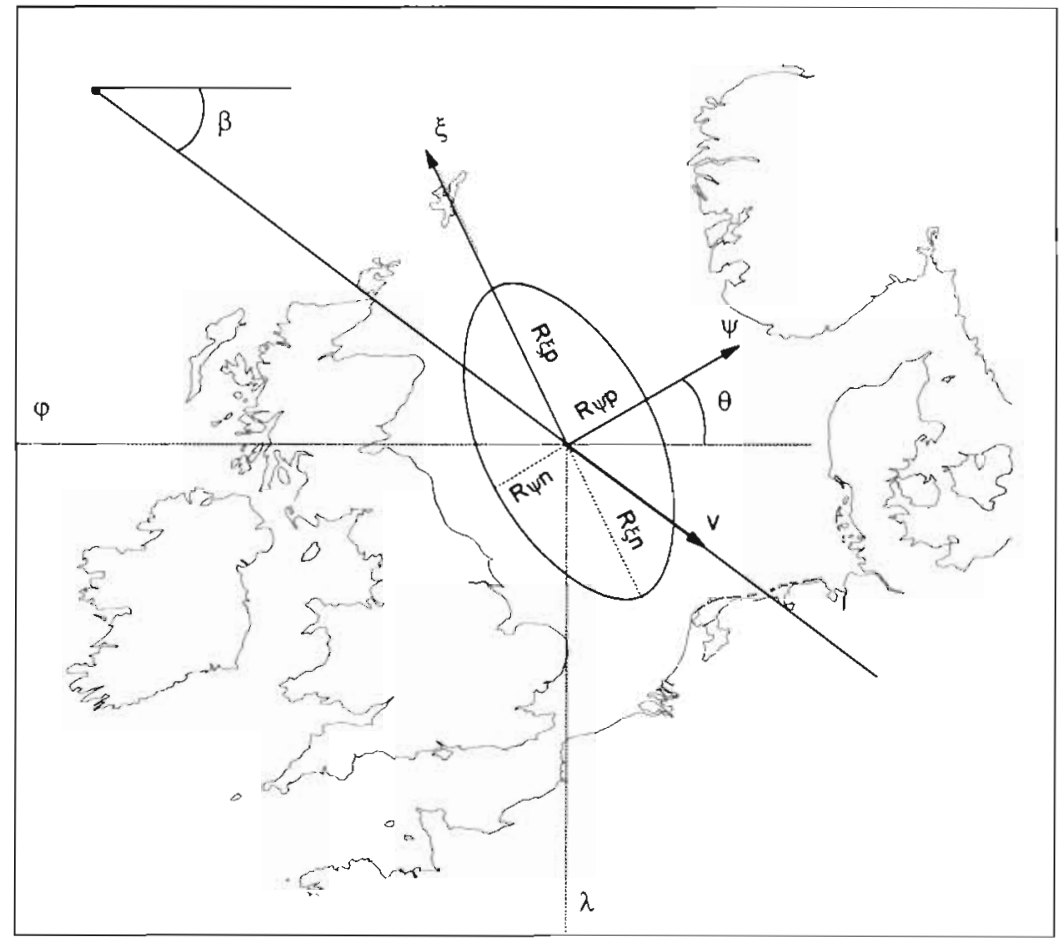

Fig. 1. Schematic representation of the storm parameters of a parametric pressure field (view from above)

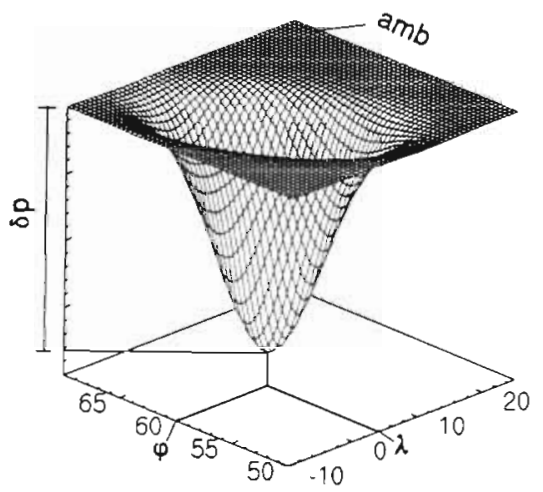

Fig. 2. Schematic representation of the storm parameters of a parametric pressure field (view from side)

\subsection{Methodology}

Below, the method to approximate 1 real pressure field is described. For more detailed information refer to Bijl (1994a):

(1) Definition of the computational grid in spherical coordinates $\left(\lambda_{1}, \varphi_{j}\right)$, where $\lambda_{i}$ is the position of grid point $(i, j)$ in degrees longitude and $\varphi_{j}$ is the position of grid point $(i, j)$ in degrees latitude.
(2) Transformation of this spherical grid into a planar grid $\left(x_{i}, y_{j}\right)$, where $x_{i}$ is the position of grid point $(i, j)$ in a longitudinal direction $(\mathrm{km})$ and $y_{1}$ is the position of grid point $(i, j)$ in a latitudinal direction $(\mathrm{km})$. The reason for this grid transformation is that the calculation of pressure on a spherical grid is very complex because of the changing size of a degree of longitude while going in a north-south direction.

(3) Calculation of the pressure at each point of the planar grid (Fig. 3). The pressure at a certain grid point $(i, j)$ is determined by:

$$
\begin{gathered}
p(i, j)=a m b-\delta p \cdot \mathrm{e}^{-\left(\frac{a^{2}}{2 r_{d}^{2}}+\frac{b^{2}}{2 r_{b-2}^{2}}\right)} \\
a=\left(x_{i}-x_{c}\right) \cos (\theta)+\left(y_{j}-y_{c}\right) \sin (\theta) \\
r_{a}=\mathrm{R} \psi n \text { if } \mathrm{a}<0 ; r_{d}=\mathrm{R} \psi \mathrm{p} \text { if } \mathrm{a} \geq 0 \\
b=-\left(x_{j}-x_{\mathrm{c}}\right) \sin (\theta)+\left(y_{j}-y_{c}\right) \sin (\theta) \\
r_{b}=\mathrm{R} \xi \mathrm{n} \text { if } \mathrm{b}<0 ; r_{b}=\mathrm{R} \xi \mathrm{p} \text { if } \mathrm{b} \geq 0
\end{gathered}
$$

where $p(i, j)$ is the pressure at grid point $(i, j)(\mathrm{Pa}) ; x_{c}$ is the position of the storm centre in a longitudinal direction $(\mathrm{km}) ; y_{c}$ is the position of the storm centre in a latitudinal direction $(\mathrm{km}) ; a$ is the distance between grid point $(i, j)$ and the storm centre in the local $\psi$-direction $(\mathrm{km}) ; \mathrm{b}$ is the distance between grid point $(i, j)$ and the storm centre in the local $\xi$-direction $(\mathrm{km})$.

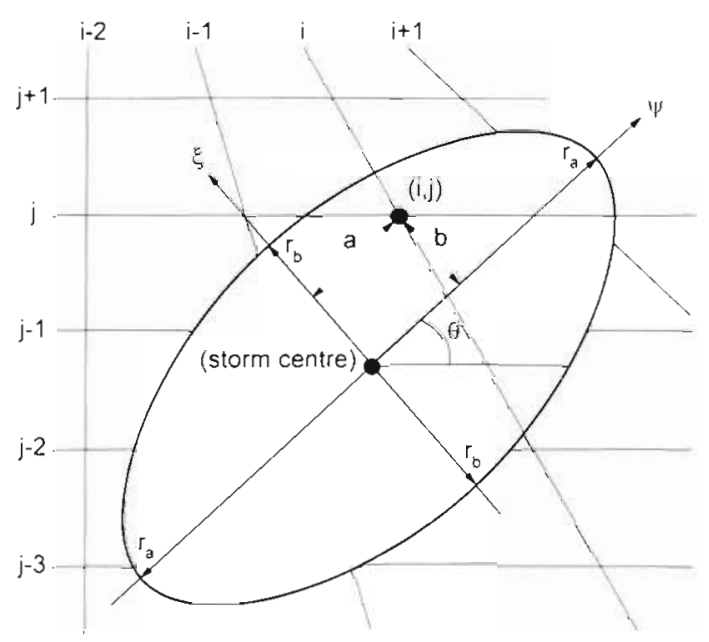

Fig. 3. Schematic representation of quantities involved in the calculation of pressure at a certain grid point $(i, j)$ of the planar grid 
(4) Transformation of the pressure data from the planar grid to the (original) spherical grid.

(5) Calculation of the corresponding wind field to the artificial (parametric) pressure field obtained, by applying the geostrophic wind speed formula. To get the wind speed at sea level, a reduction factor (65\%) and a rotation ( $15^{\circ}$ counter-clockwise) have to be used in relation to the geostrophic wind speed and wind direction (Ferier et al. 1993).

\section{MODELLING OF THE PRESENT WIND CLIMATE}

\subsection{Parameterization of the 1953 storm}

The surge generating storms in the southern part of the North Sea are modelled on the basis of the pressure fields of an extreme historic storm, namely the well-known storm of 1 February 1953. During this storm especially the south-west coast of The Netherlands was struck very hard. More than 135000 ha land was flooded and 1835 persons died. Also the east coast of England and the Thames Estuary were flooded, whereby 300 persons lost their lives. On the basis of 3-hourly pressure fields of this storm, storm parameters are derived using the concept of 'parametric storms' (Bijl 1994b). Time histories of nearly all parameters show a more or less linear behaviour between beginning and end of the storm, so it is assumed that only parameter sets are required for the first and the last pressure field of the storm (Table 1). The parameters of the intermediate pressure fields are approximated by linear interpolation. The corresponding wind fields are called the parametric 1953 storm, in contradiction to the real 1953 storm.

To illustrate that the concept of 'parametric storms' is very usable in reproducing the main characteristics of pressure fields of real storms, Fig. 4 shows 1 pressure field of both the real and the parametric 1953 storm at the same point of time.

Another indication of the usability of this concept is illustrated in Fig. 5, which shows the surge-impact of both the real and the parametric 1953 storm at station Vlissingen (The Netherlands). This surge impact is based upon storm surge computations with the Dutch Continental Shelf Model (DCSM). A description of this numerical storm surge model and the position of station Vlissingen is given in Section 5 .

\subsection{Present wind climate}

On the basis of the parametric 1953 storm, a large set of parametric storms is generated by means of a systematic variation of the storm parameters of this storm. It is required that this set is consistent with the present surge generating wind climate in the southern part of the North Sea. As described in Timmerman (1967) and Zwart (1993), not all depressions over north-west Europe generate a substantial (storm) surge in the
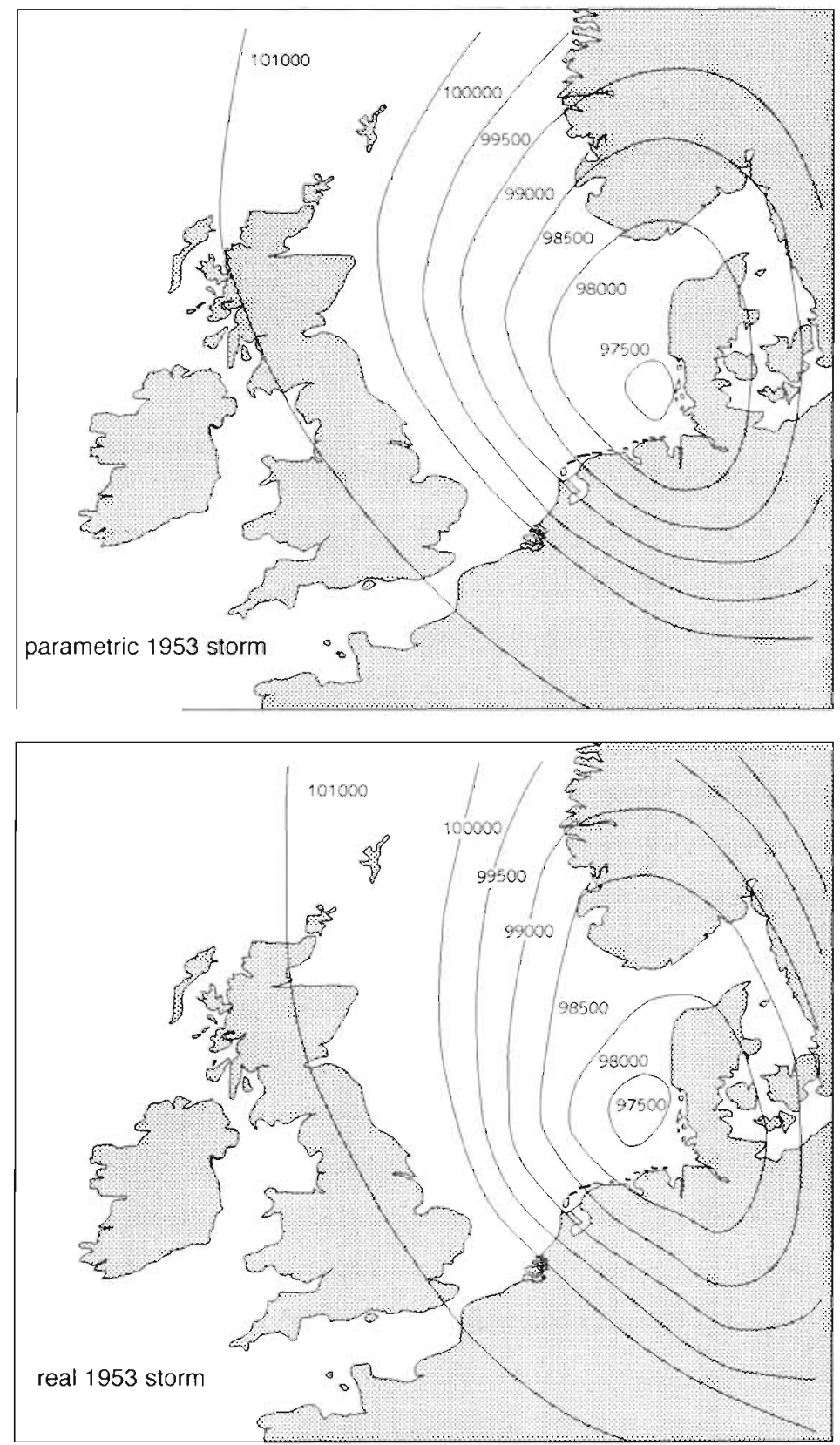

Fig. 4. Pressure field (Pa) of the real and parametric 1953 storm on 1 February $1953(0: 00 \mathrm{~h})$ 
Table 1. Parameter sets of the parametric 1953 storm

\begin{tabular}{|lrr|}
\hline Storm parameter & Begin simulation & End simulation \\
\hline$\lambda$ & $12^{\circ} \mathrm{W}$ & - \\
$\varphi$ & $664^{\circ} \mathrm{N}$ & - \\
$a m b(\mathrm{~Pa})$ & 101200 & 101200 \\
$\delta p(\mathrm{~Pa})$ & 4600 & 3000 \\
$\theta\left(^{\circ}\right)$ & 10 & 50 \\
$\beta\left(^{\circ}\right)$ & -45 & -45 \\
$V\left(\mathrm{~m} \mathrm{~s}^{-1}\right)$ & 13.0 & 6.8 \\
$R \psi \mathrm{n}(\mathrm{km})$ & 900 & 50 \\
$R \psi p(\mathrm{~km})$ & 275 & 250 \\
$R \xi p(\mathrm{~km})$ & 800 & 400 \\
$R \xi \mathrm{n}(\mathrm{km})$ & 600 & 500 \\
\hline
\end{tabular}

southern part of the North Sea. Restrictive conditions are a relatively low central pressure and a preferential course direction. The former determines the intensity of the depressions, and the latter the wind direction over the North Sea. Only northwesterly storms of sufficient intensity and duration have a substantial impact on the water level in the southern North Sea. The preferential track of these surge generating depressions is nearly always ( $85 \%$ ) situated within the area between the 2 bold lines shown in Fig. 6 .

In addition to these restrictive conditions, a sensitivity study has been carried out in which the effect of each storm parameter was examined separately (Bijl 1995b). The main findings of this study were:

- The surge response to varying the propagation speed of storms (storm parameter $v$ ) is very small in the southern part of the North Sea. This finding is consistent with Philippart et al. (1993), in which it was also found that the duration of a storm is not the most important criterion to obtain a substantial (storm) surge in the southern North Sea.
Table 2. Individual variation of the selected storm parameters (bold values: parametric 1953 storm)

\begin{tabular}{|crrrrr|}
\hline $\begin{array}{l}\varphi\left({ }^{\circ} \mathrm{N}\right) \\
\text { begin }\end{array}$ & \multicolumn{2}{c}{$\theta\left({ }^{\circ}\right)$} & $\delta p(\mathrm{~Pa})$ & \multicolumn{2}{c|}{$\mathrm{R}(\%)$} \\
begin & end & begin & \multicolumn{2}{c|}{ begin } & end \\
\hline 68.4 & 55 & 95 & 4600 & 100 & 100 \\
67.4 & 40 & 80 & 4200 & 110 & 110 \\
66.4 & 25 & 65 & 3800 & 120 & 120 \\
65.4 & 10 & 50 & & & \\
64.4 & -5 & 35 & & & \\
63.4 & -20 & 20 & & & \\
62.4 & -35 & 5 & & & \\
61.4 & & & & & \\
60.4 & & & & & \\
\hline
\end{tabular}

- To obtain a substantial (storm) surge in the southern North Sea, the direction of the storm track is not the most important factor. The determining factor turns out to be the orientation of the main wind field, a few hours before approaching the coastline. Of course the storm track must generally have been moving in the north-west sector, but the exact direction is not the decisive factor.

The afore-described restrictive conditions, combined with the findings of the sensitivity study, imply that it is not necessary to vary all the available storm parameters in order to be able to generate a realistic surge generating wind climate. A systematic variation of the following storm parameters is sufficient (Bijl 1995b) (Fig. 7):

- Storm parameter $\psi$ at the beginning of the storm, representing the (starting) latitudinal position of the storm centre. Because the course direction (storm parameter $\beta$ ) is not varied, in this case storm parameter $\psi$ also represents the position of the storm track.

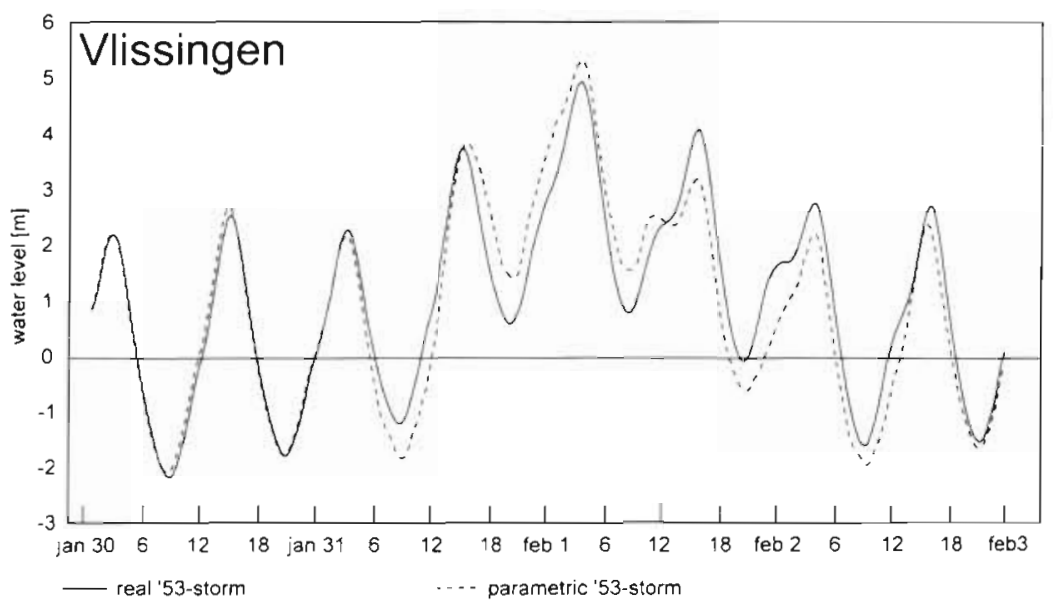

Fig. 5. Surge-impact of the real and parametric 1953 storm at station Vlissingen, The Netherlands, simulated with the Dutch Contunental Shelf Model
- Storm parameter $\theta$ at both the beginning and the end of the storm, determining the orientation of the east-west axis of the storm.

- Storm parameter $\delta p$ at the beginning of the storm, representing the pressure difference between the ambient and central pressure.

- Storm parameters R $\psi p, R \psi n, R \xi p$ and $R \xi n$ at both the beginning and the end of the storm, determining the size/shape of the storm. These 4 storm parameters are varied jointly, which means that they are treated as 1 parameter (storm parameter R). This implies that only the size of the storm is varied, while the shape remains constant. 


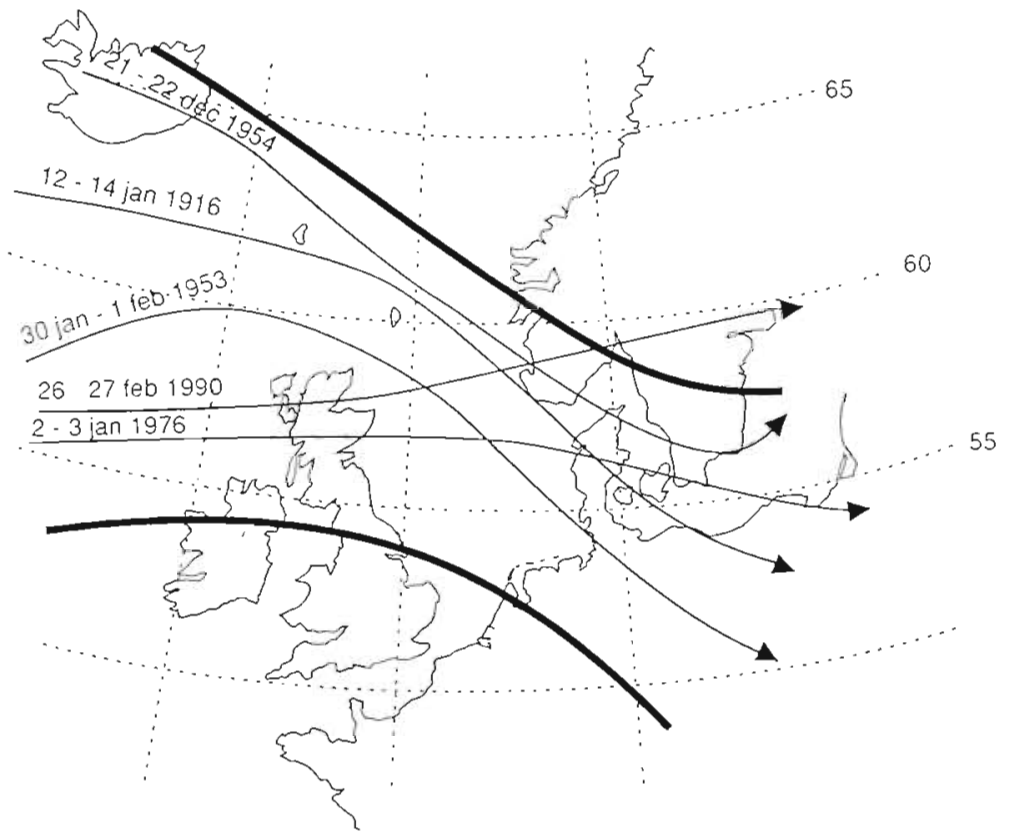

Fig. 6. Tracks of some important surge generating depressions in the 20 th century, as published by Zwart (1993). In more than $85 \%$ of all cases, the track of surge generating depressions is situated between the 2 bold lines implicitly assumed that the probability of extreme storms in this area is highly correlated with the exceedance frequencies of wind force. In order to be able to relate these exceedance frequencies to the set of parametric storms, use is made of the fact that as a result of the chosen storm parameter variations it is possible to divide the complete set of parametric storms into 9 sub-sets of 63 storms. The storms of each sub-set all originate from the same latitude and all have the same course direction (Fig. 7). These 9 sub-sets, combined with the (winter) monthly exceedance frequencies of wind force above 7 Beaufort, are schematically shown in Fig. 8a. The probability distribution of parametric storms for the present surge generating wind climate in the area of interest is derived on the basis of this combined figure, whereby a linear relationship is assumed between the latitudinal position of the storm tracks of the 9 sub-sets and the exceedance frequencies (Fig. 8b). It should be noted that,

The individual variation of each selected storm parameter is also determined on the basis of the aforedescribed restrictive conditions and findings of the sensitivity study. The result is shown in Table 2 and described in detail in Bijl (1995b). On the basis of these variations, the complete set of parametric storms which is used to model the present surge generating wind climate in the southern part of the North Sea consists of 567 storms.

However the individual storms of this set of parametric storms do not all have equal chances of occurrence in the southern North Sea area. Therefore, to model the present surge generating wind climate in this area, a probability distribution of these storms is also required. Since the aim of the present paper is to explore the sensitivity of the surge in the southern North Sea to a possible wind climate change in this area, the exact probability distribution is not a matter of major concern. Therefore, it was decided to approximate this probability distribution with the help of the (winter) monthly exceedance frequencies of wind force above 7 on the Beaufort scale in the North Sea (Korevaar 1990). So, it is

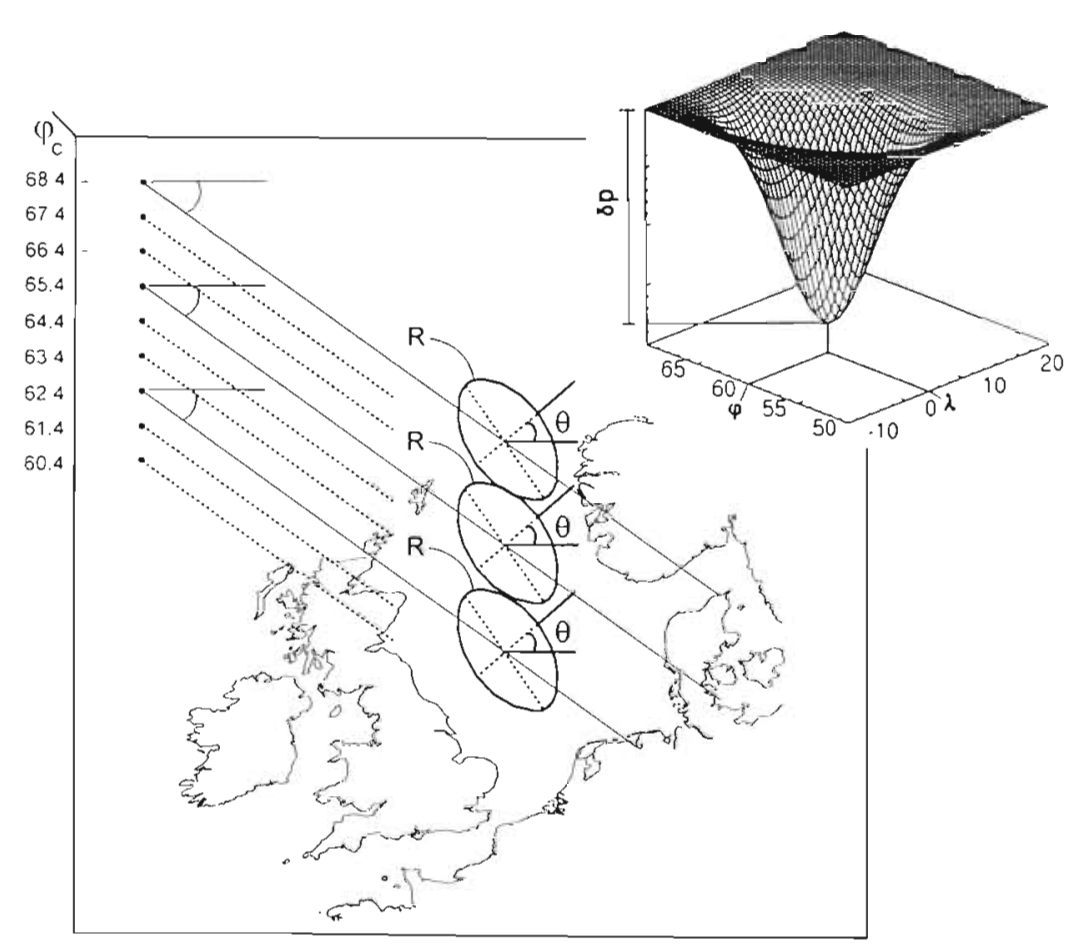

Fig. 7 Schematic representation of the storm parameter variations required to generate a realistic surge generating wind climate in the southern North especially for the higher latitudes, this (linear) probability distribution overestimates the exceedance frequencies shown in Fig. 8a. As a result, the sub-sets of 


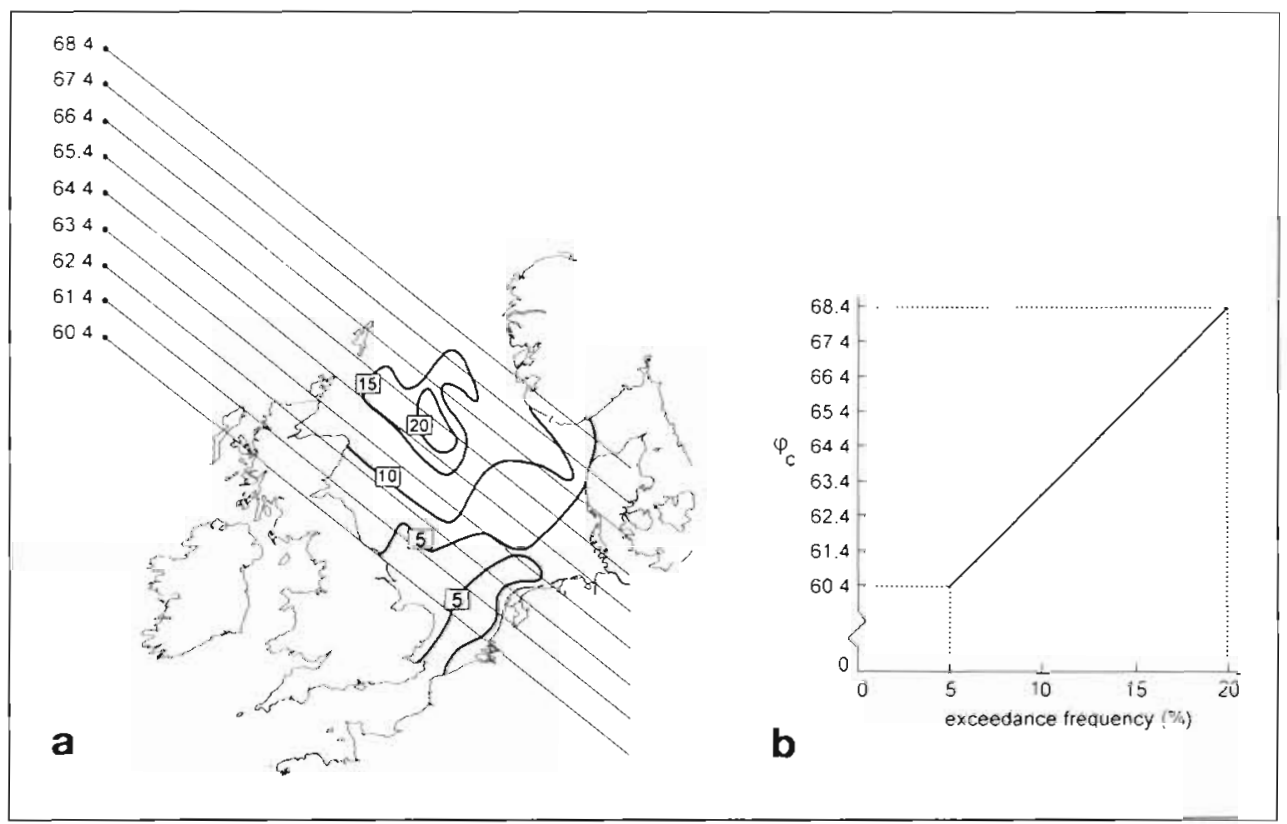

Fig. 8. (a) Isolines of (winter) monthly exceedance frequencies of wind force above 7 Beaufort, combined with tracks of the 9 sub-sets of 63 parametric storms. (b) Probability distribution of parametric storms for the present surge generating wind climate in the southern North Sea

storms with (north-westerly) tracks over the North Sea are overestimated, which means that the present surge generating wind climate in the southern North Sea modelled in this way is on the extreme side.

\section{SURGE IMPACT OF THE WIND CLIMATE CHANGE}

\subsection{Storm surge model}

The surge-impact of the set of parametric storms is determined with the DCSM (Verboom et al. 1992, Gerritsen et al. 1995). This is a non-linear model for tide flow and wind-induced flow on the north-west European Continental Shelf and is mainly used for storm surge computations, water quality computations and for generation of boundary conditions for smaller models. The model covers a large part of the north-west European Continental Shelf: from $48^{\circ}$ to $62^{\circ} 20^{\prime} \mathrm{N}$ and $-12^{\circ}$ to $13^{\circ} \mathrm{E}$ (Fig 9). The grid size of the original DCSM is $1 / 8^{\circ} \mathrm{E}$ by $1 / 12^{\circ} \mathrm{N}$, with the north-west corner of the model cut off. The model used in this study has a grid twice this resolution (in both directions) and is called DCSM-16, though henceforth in this paper it will be referred to simply as DCSM.

The model is based on the WAQUA program package at Rijkswaterstaat, which is a general purpose program system for solving depth-integrated flow and transport problems in general geometries. In a spherical coordinate system the equations to be solved are (Gerritsen et al. 1995):

$$
\begin{aligned}
& u_{l}+\frac{u}{R \cos \varphi} u_{\lambda}+\frac{v}{R \cos \varphi}(u \cos \varphi)_{\varphi}-2 \omega v \sin \varphi+ \\
& \frac{g u \sqrt{u^{2}+v^{2}}}{C^{2}(h+\zeta)}+\frac{g}{R \cos \varphi} \zeta_{\lambda}+\frac{1}{\rho R \cos \varphi} p_{\lambda}= \\
& \frac{\rho_{\mathrm{a}} C_{\mathrm{d}} u_{10} \sqrt{u_{10}^{2}+v_{10}^{2}}}{\rho(h+\zeta)} \\
& v_{t}+\frac{u}{R \cos \varphi} v_{\lambda}+\frac{v}{R} v_{\varphi}+\frac{u^{2} \tan \varphi}{R}+2 \omega u \sin \varphi+ \\
& \frac{g v \sqrt{u^{2}+v^{2}}}{C^{2}(h+\zeta)}+\frac{g}{R} \zeta_{\varphi}+\frac{1}{\rho R} p_{\varphi}=\frac{\rho_{a} C_{\mathrm{d}} v_{10}}{\rho(h+\zeta)} \sqrt{u_{10}^{2}+v_{10}^{2}} \\
& \zeta_{t}+\frac{1}{R \cos \varphi}\left\{[(h+\zeta) u]_{\lambda}+[(h+\zeta) v \cos \varphi]_{\varphi}\right\}=0
\end{aligned}
$$

where $\lambda$ and $\varphi$ are the longitude and latitude coordinates respectively; $u$ and $v$ are the components of depth-mean current in longitude and latitude directions respectively; $h$ is the water depth below reference level (MSL); $\zeta$ is the water level above reference level (MSL); $w$ is the angular speed of the earth; $g$ is the gravitational constant; $C$ is the Chézy bottom friction parameter; $R$ is the radius of the earth; $u_{10}$ and $v_{10}$ are the components of wind speed in longitude and latitude directions (at $10 \mathrm{~m}$ height) respectively; $\mathrm{C}_{\mathrm{d}}$ is the wind-drag coefficient; $\rho$ and $\rho_{a}$ are the densities of water and air respectively; $p$ is the atmospheric pressure; and $t$ is time.

A detailed explanation of Eqs. (2) to (4) can be found in Leendertse (1967) and Stelling (1984). It may be helpful, however, to offer here a brief indication of 


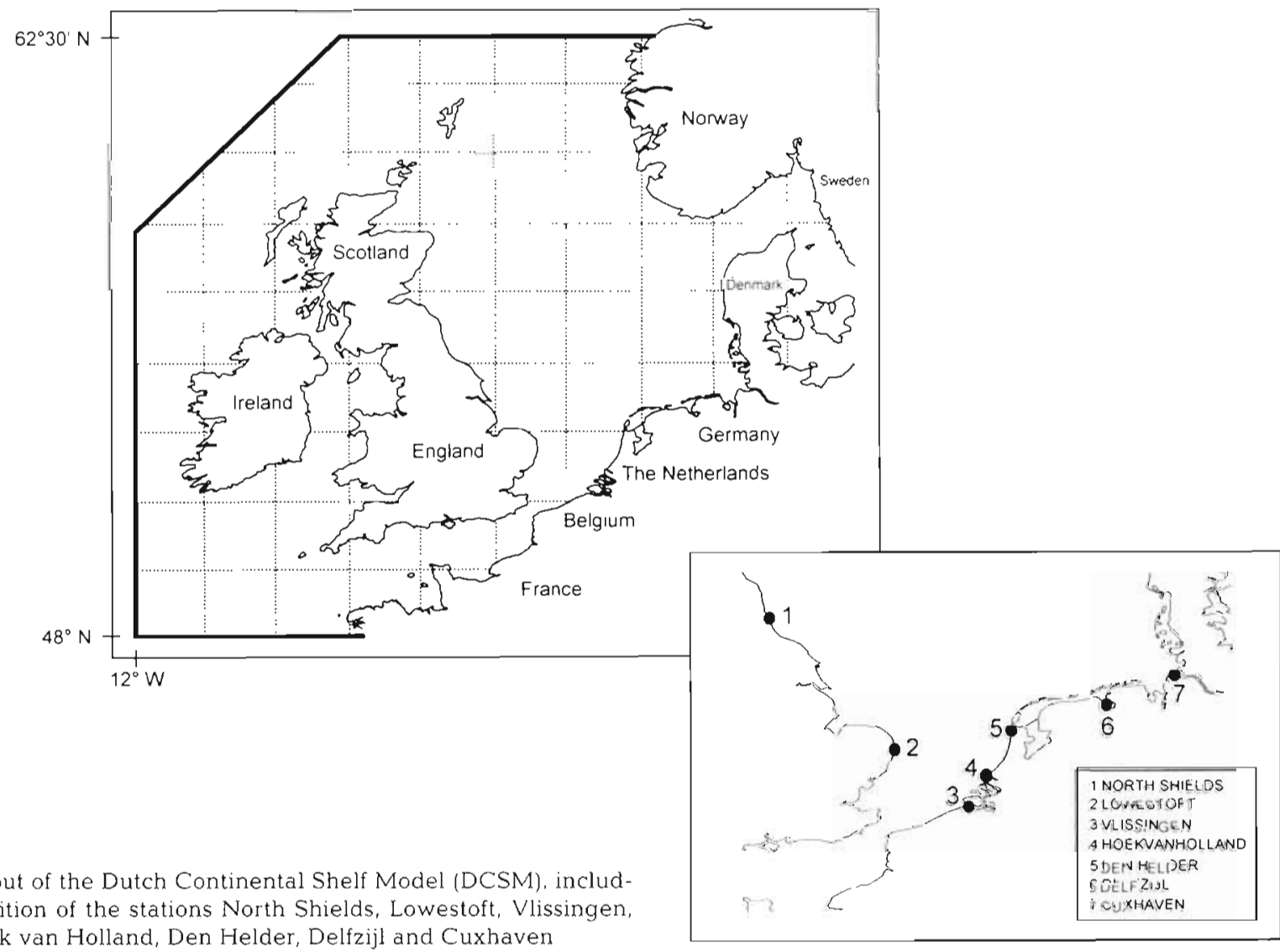

Fig. 9. Layout of the Dutch Continental Shelf Model (DCSM), includ ing the position of the stations North Shields, Lowestoft, Vlissingen, Hoek van Holland, Den Helder, Delfzijl and Cuxhaven

helpful, however, to offer here a brief indication of their physical meaning. Thus, given that the subscripts $t, \lambda$ and $\varphi$ denote partial differentiation, Eqs. (2) \& (3) may be considered to be momentum equations with terms relating to the water motion on the left and the wind forcing term on the right. Simply speaking, the time derivatives $u_{t}$ and $v_{t}$ of the 2 components of water velocity can be determined implicitly from these, whereas the continuity equation (Eq. 4) is used to compute the rate of change $\zeta_{l}$ of the water elevation. These equations are very suitable for modelling the tidal flows and the effects of meteorologically induced variations in water level (Leendertse 1967). They are solved with an ADI method (Stelling 1984) on a staggered grid and supplemented by boundary conditions at the closed boundaries (coastlines) and at the open sea boundaries of the model (tidal boundary conditions). For more detailed information refer to Verboom et al. (1992) and Gerritsen et al. (1995).

\subsection{Storm surge computations}

For the complete set of parametric storms, storm surge computations are carried out with the DCSM and only the meteorological effect is used as boundary condition. This means that tidal effects are not taken into account, which implies that the simulation results are not influenced by the different tidal ranges of the various stations in the model or the timing of the storm with respect to the astronomical tide of the various stations in the model. This has the advantage that the number of storm surge computations can be restricted to 567 (number of parametric storms), because, in this way, there is no need to carry out an enormous amount of storm surge computations in order to exclude tidal effects on the simulation results. A (minor) disadvantage is the fact that the non-linear interaction between tide and storm surges, which may lead to both reduction and amplification of storm surges, is not taken into account. Generally speaking, this effect increases a storm surge at rising tide and decreases this surge at high tide (Bijl 1994b). As described in the following part of this section, this disadvantage will be counterbalanced by applying a correction factor which takes this interaction effect between tide and storm surge into account.

The results of the storm surge computations (time series) are performed for the stations North Shields and Lowestoft on the British coast, stations Vlissingen, 
Hoek van Holland, Den Helder and Delfzijl on the Dutch coast and station Cuxhaven on the German coast. The position of these stations is visualised in Fig. 9. The simulation period of the storm surge computations runs from 30 January 1953, 0:00 h to 3 February 1953, 0:00 h. The first day is used to remove initial disturbances, so only the results from 31 January and subsequent days have been used for analyzing the results.

In order to analyze these results, first the maximum storm surge effect of each individual storm is computed for

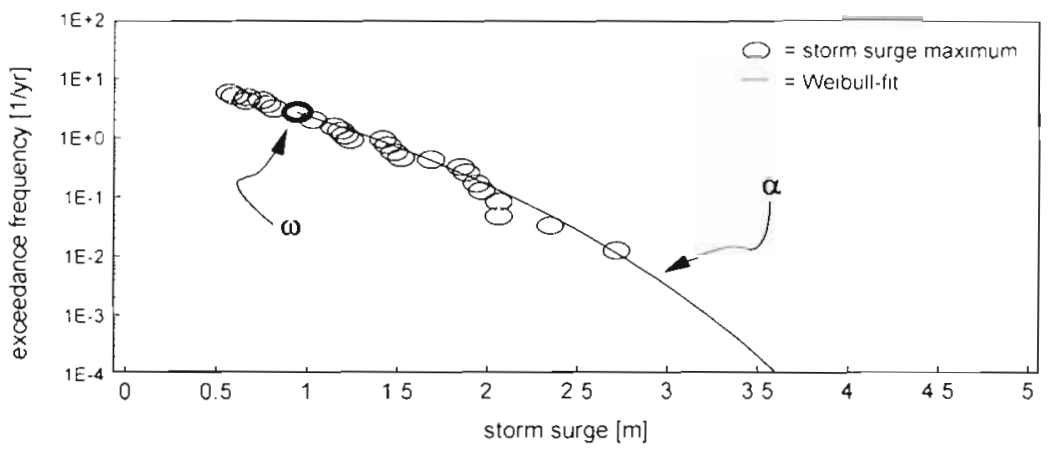

Fig. 10. Schematic representation of the estimation of exceedance frequencies of storm surge maxima on the basis of a conditional 2-parameter Weibull frequency distribution (see Eq. 5)

each selected station. Subsequently,

for station Hoek van Holland, estimates of exceedance frequencies of these storm surge maxima are made on the basis of the following (conditional) 2-parameter Weibull frequency distribution, which approximates exceedance frequency curves above a certain threshold $\omega$ (Fig. 10):

$$
\mathrm{P}|\mathrm{x}>h| \mathrm{X}>\omega \mid=\mathrm{e}^{-\left(\frac{h}{\sigma}\right)^{\alpha}+\left(\frac{w}{\sigma}\right)^{\alpha}}
$$

where $h$ is a certain storm surge maximum; $\alpha$ is the parameter which determines the shape or curvature of the frequency distribution; $\sigma$ is the parameter which determines the scale of the frequency distribution; and $\omega$ is the threshold value. So $P[x>h \mid x>\omega]$ is the chance of exceedance of a certain storm maximum $h$, given a threshold value $\omega$.

The estimates of exceedance frequencies are made over a wide range of thresholds, with $\alpha$ and $\sigma$ estimated for each threshold. The optimal combination of threshold and shape and scale parameters is determined on the basis of the 'extreme storm level' of station Hoek van Holland. At first instance, this 'extreme storm level' has been assessed by the Delta Committee, which was installed by the Dutch Minister of Public Works shortly after the 1953 flood disaster (Maris 1961). One of the primary achievements of this Delta Committee was to set different safety standards for various parts of the Dutch coast (depending on the economic importance of the area). Along the central coast of The Netherlands a safety standard was agreed with a return period of $10000 \mathrm{yr}$, which means that in a lifetime of $100 \mathrm{yr}$ there is a $1 \%$ chance that flooding will occur. Recently, a reassessment of the Delta Committee's findings has been done, using longer records, new statistical methods and physical, meteorological and hydrodynamical models (van Urk 1993, de Ronde et al. 1995). For station Hoek van Holland, the revised 'extreme storm level' (with a return period of $10000 \mathrm{yr}$ ) is $5 \mathrm{~m}$ above NAP (Dutch Ord- nance Datum). This extreme storm level can be seen as a combination of storm surge effect, tidal effect and interaction effect between storm surge and tide (Bijl $1994 \mathrm{~b})$. The storm surge computations with the DCSM, however, are carried out without tidal influence and thus do not include tidal and interaction effects. Therefore, to obtain an extreme storm level which is comparable to the results of the storm surge computations, mean high-water $(1.11 \mathrm{~m})$ and the interaction effect between storm surge and tide (0.27 m; Philippart 1994) are, respectively, subtracted from and added to the official extreme storm level of station Hoek van Holland. This 'extreme storm surge level', which has an exceedance frequency of $10^{-4}$ and is $4.16 \mathrm{~m}$ above NAP, is used to derive the optimal combination of Weibull parameters for station Hoek van Holland. On the basis of this Weibull parameter set of Hoek van Holland, the exceedance frequencies of storm surge maxima of all selected stations are estimated with the help of Eq. (5) (Fig. 11). This approach is consistent with the approach described in Philippart et al. (1993) and van Urk (1993), in which Hoek van Holland also serves as a reference (calibration) station for other Dutch coastal stations.

\subsection{Wind climate change}

In order to describe the surge-impact of both scenarios of wind climate change in the southern part of the North Sea, first the surge-impact of the present wind climate is determined. This is done by combining the probability distribution of storms in this area (Fig. 8b) with the frequency distribution of storm surge maxima of the various stations (Fig. 11). To combine these 2 distributions, use is made of the fact that the storm surge maxima of each individual station can be split up into 9 sub-sets (which correspond to the 9 sub-sets of para- 

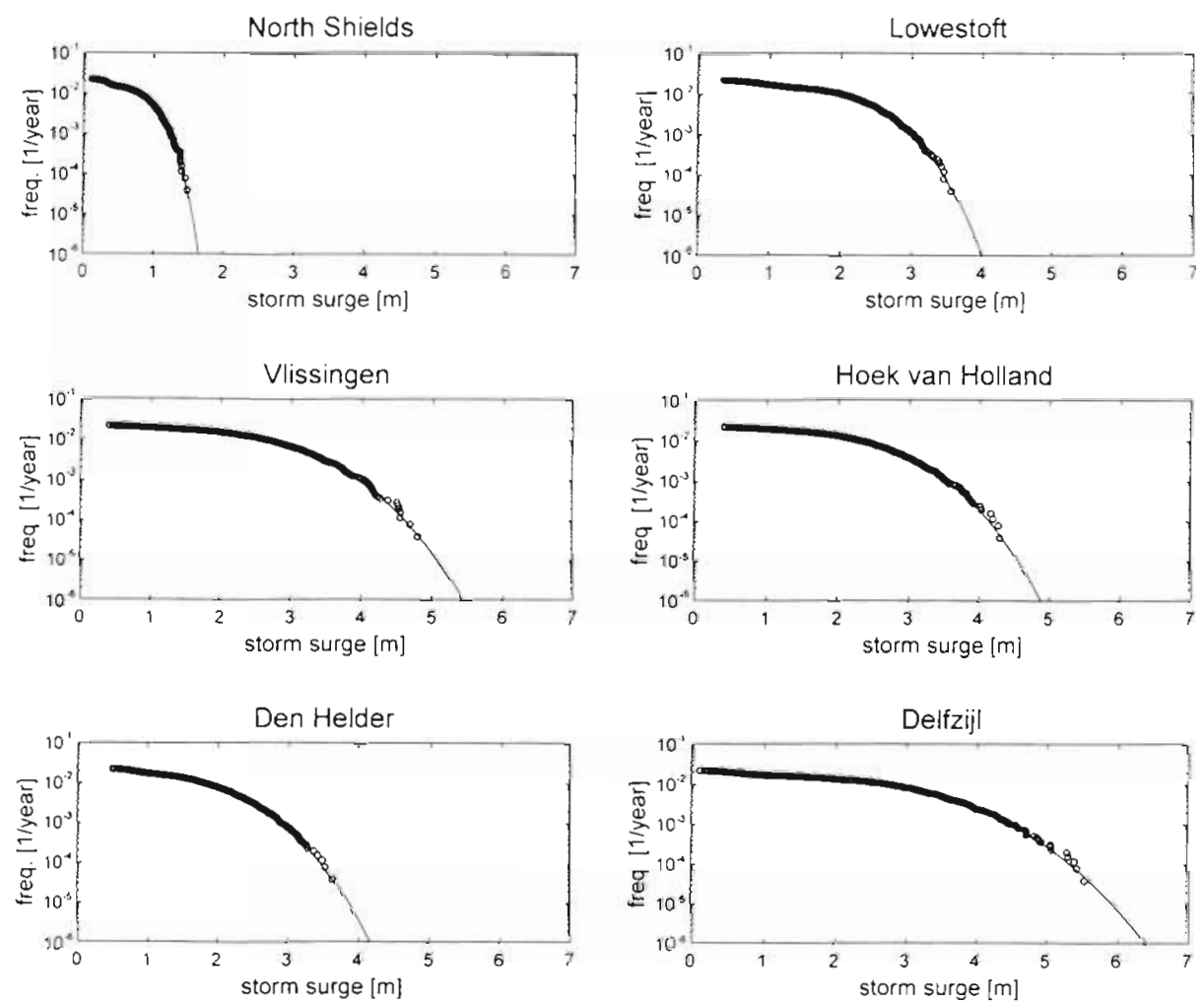

Fig. 11 Estimates of exceedance frequencies of storm surge maxima; $(0)$ storm surge maxima; $(-)$ Weibull-fit

metric storms as described in Section 4.2), For each of these 9 sub-sets, exceedance frequencies can be estimated with the help of Eq. (5) (on the basis of the same Weibull parameter set as used for the complete set of storm surge maxima). According to the probability distribution of storms in the southern North Sea (Fig. 8b), all these 9 frequency distributions of storm surge maxima are related to a specific exceedance frequency. After applying these (normalized) exceedance frequencies to the frequency distributions, combination of the 9 'adjusted' frequency distributions of storm surge maxima obtained in this way provides the surgeimpact of the present wind climate at a certain station (Fig. 12, solid líne). For more detailed information refer to Bijl (1995a).

Section 2.3, Scenario 1 states that the possible wind climate change in the southern part of the North Sea will consist of a northward shift of $2^{\circ}$ latitude of the entire wind climate system in this area. The surgeimpact of the wind climate which might develop as a

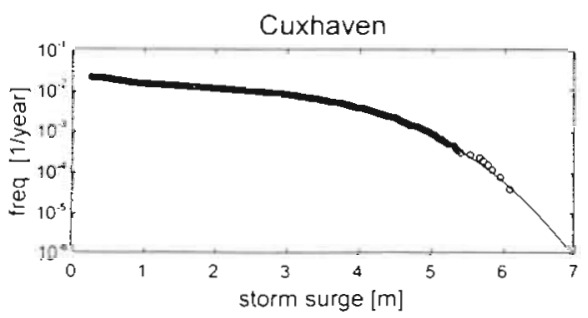

result of this scenario is determined by shifting the present probability distribution of parametric storms in the southern part of the North Sea (Fig, 8b) 2 degrees in a northward direction. The most southern monthly exceedance frequencies of this new distribution have been set to $5 \%$. Combining this new (future) probability distribution with the frequency distributions of storm surge maxima of the various stations (in the same way as described above) provides this surgeimpact (Fig. 12, dotted line).

Fig. 12 shows clearly that a northward shift of $2^{\circ}$ latitude of the present surge generating wind climate in the southern part of the North Sea (as modelled in this paper) will have just a small impact on the storm surge maxima in this area. This impact will consist of a slight decrease of the exceedance frequencies of these maxima and is uniformly distributed through the area of interest.

Scenario 2, which is described in Section 2.3, states that the possible wind climate change in the southern 
part of the North Sea will consist of an increase of the intensity of storms in this area. The surge-impact of the wind climate which might develop as a result of this scenario is determined by means of varying storm parameter $\delta p$, which represents the pressure difference between ambient and central pressure of parametric storms. Because it is assumed that in this case the simulation results of a particular storm can be applied directly to the complete set of storms, only the parametric 1953 storm has been used to determine the surge-impact of this scenario of wind climate change. The storm surge computations, carried out with the DCSM, are similar to the storm surge computations described in Section 5.2, where only the meteorological effect is taken as boundary condition. Fig. 13 shows the simulation results of stations on the Dutch coast by means of a graphical presentation of the relationship between maximum storm surge and maximum wind speed during a storm. The latter is, of course, directly related to the storm intensity. From this relationship it follows that a relatively small change of the wind speed in the southern North Sea (which is related to the storm intensity) will have a relatively large influence on the storm surge maxima in this area. A $10 \%$ increase of the wind speed, as stated in the ISOS-scenarios of climatic change (Peerbolte et al. 1991), will result in an increase of these maxima of about $0.5 \mathrm{~m}$. Of course, one must be aware of the fact that the above-described conclusion depends very much on the assumption that in this particular case the simulation results of 1 storm can be applied directly to the complete set of storms.
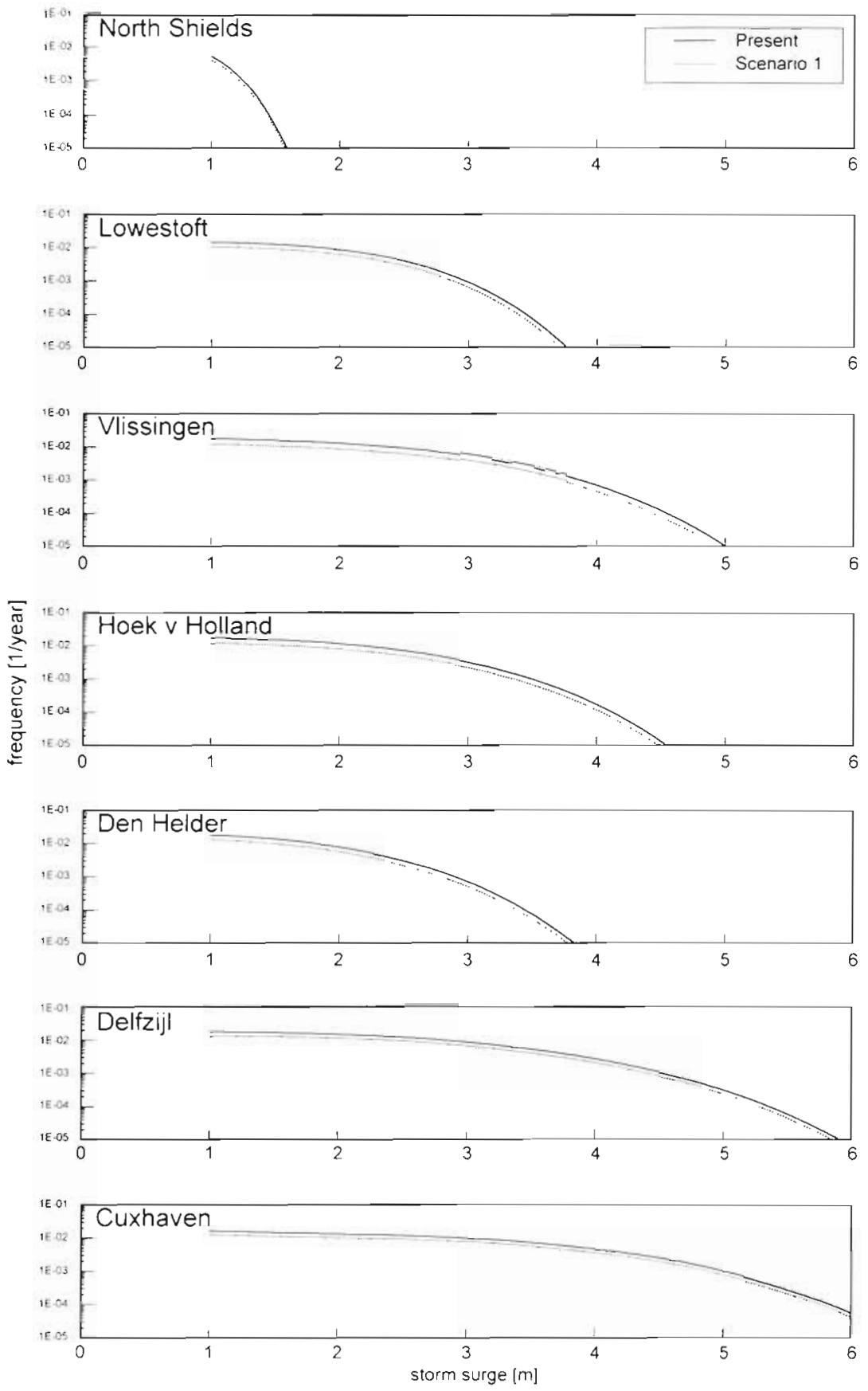

Fig. 12. Surge-impact of the present and future (Scenario 1) wind climate in the southern North Sea

\section{DISCUSSION AND CONCLUSIONS}

The aim of the present paper was to aquire quantitative insights into the impact on storm surges of a possible change of the wind climate in the southern part of the North Sea. In this final section, some concluding remarks will be made on the basis of subjects which play an important role in obtaining these insights.

\subsection{Prediction of climatic changes}

At present, a large number of numerical climate models is available, ranging from simple earth-averaged, time-independent (temperature) models up to high-resolution, 3-dimensional, time-dependent models (GCMs). In essence, these models translate conceptual ideas into quantitative statements. They are, of 

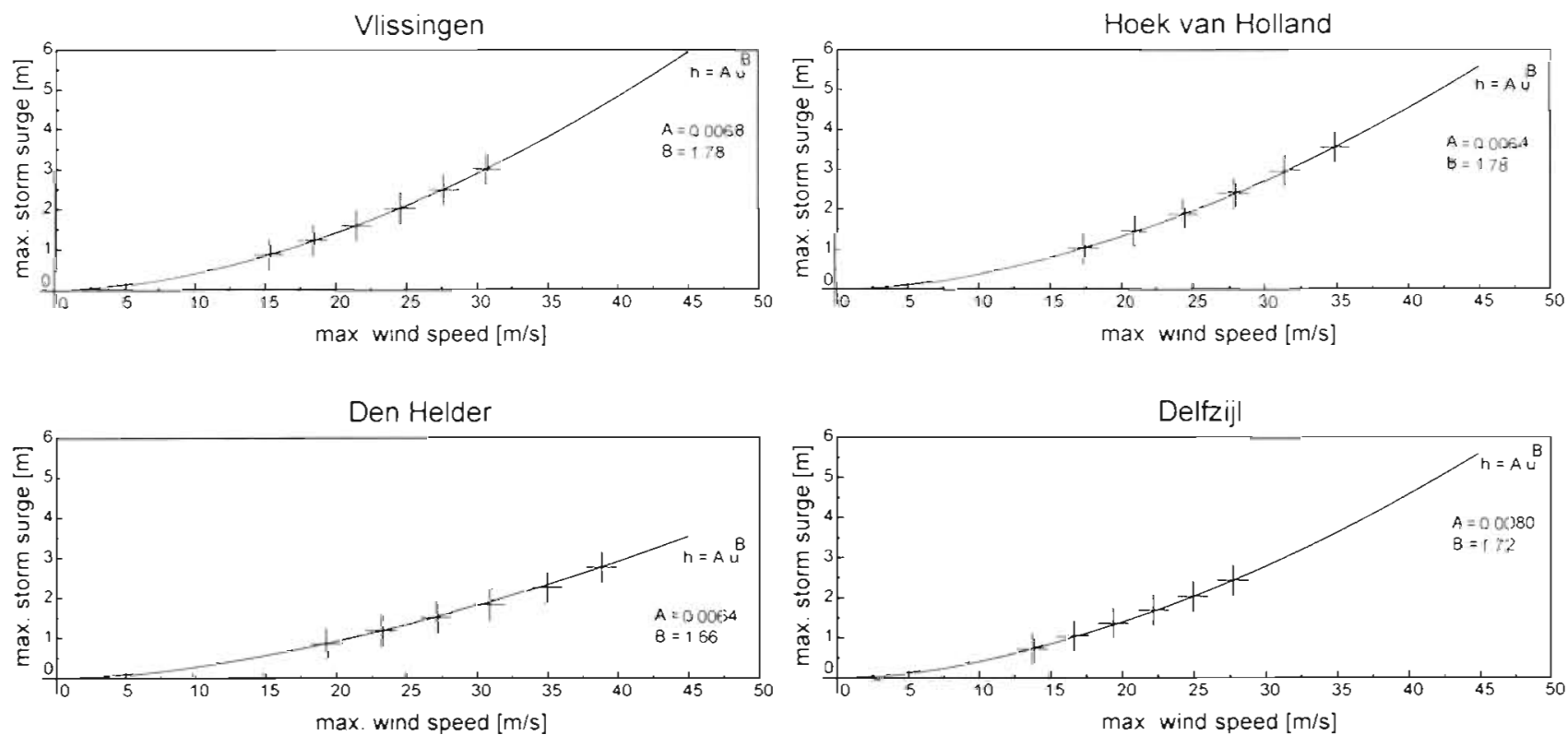

Fig. 13. Relationship between storm surge maxima $(h)$ and maximum wind speed $\left(u_{10}\right)$ during a storm

course, not able to simulate the full complexity of reality, but produce the logical consequences of a specific set of (plausible) assumptions. Up to now, even the most elaborate GCMs have not been able to simulate unambiguously the regional distribution of climatic changes associated with an increasing carbon dioxide concentration. This is especially true for possible changes of (regional) wind climate systems; the simulation results are not unequivocal. Therefore, to nevertheless explore the consequences of a possible wind climate change, which is of great importance for the low lying countries around the North Sea, the best alternative is to specify plausible scenarios of possible wind climate change for this particular area and then to evaluate the sensitivity of the storm surge levels to this wind climate change. In this paper, the following 2 scenarios have been investigated, which are assumed to reflect the extremes of the most important possible wind climate changes: Scenario 1 - the wind climate change in the southern part of the North Sea will consist of a northward shift of $2^{\circ}$ latitude of the entire wind climate system in this area; and Scenario 2-the wind climate change in the southern part of the North Sea will consist of an increase of the intensity of storms in this area.

\subsection{Modelling of a regional wind climate}

Because reality is too complex to simulate, it is first necessary to define which variables/characteristics of storms have to be taken into consideration to model the (present) surge generating wind climate in the south- ern part of the North Sea. The result is summed up in the concept of 'parametric storms', which (in essence) considers the characteristics of a storm to be conditional upon 11 parameters (such as storm intensity, storm track, propagation speed, etc.). As illustrated in Section 4.1, this concept provides a very quick and usable method to reproduce (in a numerical way) the main characteristics of real storms.

The (present) surge generating wind climate in the southern North Sea is modelled by means of 567 parametric storms, accompanied by a probability distribution of these storms in this area. These 567 storms are all derived from the 'parametric version' of the wellknown extreme storm of 1953 , which implies that the set of parametric storms, obtained in this way, is on the extreme side. In addition, the probability distribution of storms in the southern North Sea overestimates the exceedance frequencies, especially for storms at higher latitudes (see Fig. 8). Both effects lead to the conclusion that the (present) surge generating wind climate in the southern North Sea, modelled in this way, is on the safe (extreme) side.

\subsection{Simulation of storm surges}

To determine the surge-impact in the southern part of the North Sea as a result of the large set of (parametric) storms, use is made of the Dutch Continental Shelf Model, which is one of the most well-calibrated numerical storm surge models for this particular area. The model is extensively used for simulation of tide and storm surge on the northwest European Continen- 
tal Shelf and has proved to be very capable in simulating these phenomena. North Sea coastal stations for example, show for storm surge computations a standard deviation on the order of $20 \mathrm{~cm}$ for given wind conditions. Determining the above-described surgeimpact means in principle that an enormous amount of storm surge computations have to be carried out in order to exclude tidal effects on the simulation results. The latter is necessary because the various stations in the model have different tidal ranges and because the timing of the storms differs with respect to the astronomical tide of the various stations in the model.

The number of storm surge computations could, however, be reduced simply to the number of (parametric) storms by using correction factors to take account of tidal effects, thus achieving great savings of expensive computer time. It must be noted, however, that the interaction between tide and storm surge is nonlinear and can lead to both reduction and amplification of surge levels. The exact size of the interaction effect is determined by the size of the tidal range and the surge height. As described in Bijlsma (1989), generally it increases the surge height at rising tide and decreases the surge height at high tide. A first attempt to quantify these effects is described in Philippart (1994), but more insight is needed.

\subsection{Surge-impact of wind climate change}

The surge-impact of the surge generating wind climate which might develop in the southern North Sea as a result of Scenario 1 is determined by shifting the probability distribution of parametric storms $2^{\circ}$ in a northward direction. This relatively large northward shift ( $2^{\circ}$ in a latitudinal direction is about $220 \mathrm{~km}$ ), combined with the fact that the modelled wind climate in the southern North Sea is on the extreme side, implies that for this scenario of possible wind climate change the surge-impact can be regarded as the upper limit. The surge-impact of the surge generating wind climate which might develop in the southern North Sea as a result of Scenario 2 is determined by a variation of the pressure difference between ambient and central pressure of parametric storms. It should be noted that to determine this surge-impact it was assumed that the results for a particular storm can be applied directly to the complete set of (parametric) storms.

\subsection{Summary}

- A relatively large northward shift of 2 degrees of latitude of the present surge-generating wind climate in the southern part of the North Sea will have just a small impact on the storm surge maxima in this area.

- A relatively small increase of the intensity of surgegenerating depressions in the southern part of the North Sea will have a relatively large impact on the storm surge maxima in this area.

The surge-impact of a possible change of the wind climate in the southern part of the North Sea is very dependent on the scenario of wind climate change which is used.

\section{LITERATURE CITED}

Bijl W (1994a) Testing program 'Wind' Rijkswaterstaat, National Institute for Coastal and Marine Management, The Hague

Bijl W (1994b) The parameterization of the 1953 storm. Rijkswaterstaat, National Institute for Coastal and Marine Management, The Hague

Bijl W (1995a) Impact of a wind climate change on the surge in the southern part of the North Sea. Rijkswaterstaat, National Institute for Coastal and Marine Management, The Hague, report no. RIKZ-95.016

Bijl W (1995b) EG.EPOCH, verzamelbundel resultaten. R.jkswaterstaat, National Institute for Coastal and Marine Management, The Hague (in Dutch)

Bijlsma AC (1989) Investigation of surge-tide interaction in the storm surge model CSM-16. Delft Hydraulics, Delft, report no. Z311

Carter DJT, Draper L (1988) Has the North-east Atlantic become rougher? Nature 332:494

de Ronde JG, Dillingh D, Philippart ME (1995) Design criterı along the Dutch coast. Proceedings UNESCO workshop HYDROCOAST 95. Bangkok, p 138-151

Ferier P, Holthuijsen LH, Eldeberky Y, Booij N (1993) Extreme parametric storms for waves in the southern North Sea. Delft University of Technology, Delft, report no. 8-93

Gerritsen H, de Vries JW, Philippart ME (1995) The Dutch Continental Shelf Model. Quantitative skill assessment for codstal ocean models. Coast Estuar Stud 48:425-467

Held IM (1993) Large-scale dynamics and global warming Bull Am Meteorol Soc 74:229-241

Hogben $N$ (1995) Increases in wave heights over the North Atlantic: a review of the evidence and some implications for the Naval Architect. Trans R Inst Naval Architects 137: $93-115$

Houghton JT, Callander BA, Varney SK (1992) Climate change 1992. The Supplementary Report to the IPCC Scientific Assessment. Cambridge University Press, Cambridge

Houghton JT, Jenkins GJ, Ephraums JJ (1990) Climate change. The IPCC Scientific Assessment. Cambridge Unıversity Press, Cambridge

Können GP (1993) Climate prediction and climate predictability. Royal Netherlands Meteorological Institute (KNMI), de Bilt, report no. KO 93-02

Korevaar CG (1990) North Sea climate, based on observations from ships and lightvessels. Kluwer Academic Publishers. Dordrecht

Leendertse JJ (1967) Aspects of a computational model for long-period waterwave propagation. Rand Corporation, Memorandum RM-5294-PR

Maris AG (1961) Rapport Deltacommissie, eindverslag en interimadviezen. Staatsdrukkerij - en Uitgeverijbedrijf, 'sGravenhage (1n Dutch) 
Munich Re (1990) Windstorm. Munchener Rückversicherungs-Gesellschaft, München

Peerbolte EB, de Ronde JG, de Vrees LPM, Mann M, Baarse G (1991) Impact of sea level rise on society, a case study for The Netherlands. Rjjkswaterstaat, Tidal Waters Division, The Hague, report no. GWAO 90-016

Philippart ME (1994) Personal Memorandum. Rijkswaterstaat. National Institute for Coastal and Marme Management, The Hague (in Dutch)

Philippart ME, Pwa ST, de Ronde JG (1993) De basispenlen lang de Nederlandse kust, fysisch onderzoek. Rijkswaterstaat, Tidal Waters Division, The Hague, report no. DGW93.025 (in Dutch)

Schuurmans CJE (1995a) Klimaat en stormen. Meteorologica $4: 7-12$ (in Dutch)

Schuurmans CJE (1995b) The world heat budget: expected changes. In: Eisma D (ed) Climate change, impact on coastal habitation. Lewis Publishers, Boca Raton, p 1-15

Siegmund, PC (1990a) The effect of a doubling of atmospheric $\mathrm{CO}_{2}$ on the stormtracks in the climate of a General Circulation Model. Royal Netherlands Meteorological Institute (KNMI), de Bilt, report no. WR 90-01

Siegmund PC (1990b) The effect of a doubling of atmospheric $\mathrm{CO}_{2}$ on the frequency distribution of circulation types over Europe as simulated by a General Circulation Model (per-

Editor: H. von Storch, Geesthacht, Germany sonal memorandum). Royal Netherlands Meteorological Institute (KNMI), de Bilt, report no. DM-90-12

Stelling GS (1984) On the construction of computational methods of shallow water flow problems. Rijkswaterstaat, The Hague, Rijkswaterstaat Communicatıons no. 35

Stouffer RJ, Manabe S, Vinnikov KY (1994) Model assessment of the role of natural variability in recent global warming. Nature 367:634-636

Timmerman H (1967) Onderzoek naar de banen behorende bij depressies, die hoge waterstanden veroorzaken in het noorden van Nederland. Royal Netherlands Meteorological Institute (KNMI), de Bilt, report no. V-200 (in Dutch)

van Urk A (1993) De basispeilen langs de Nederlandse kust, eindverslag. Rijkswaterstaat, Tidal Waters Division, The Hague, report no. DGW-93.026 (in Dutch)

Verboom GK, de Ronde JG, van Dijk RP (1992) A fine grid tidal flow and storm surge model of the North Sea. Cont Shelf Res 12:213-233

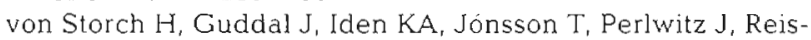
tad M, de Ronde JG. Schmidt H, Zorita E (1993) Changing statistics of storms in the North Atlantic? Max-PlanckInstitut für Meteorologie, Hamburg, report no. 116

Zwart B (1993) De stormvloed van 1 februari 1953. Royal Netherlands Meteorological Institute (KNMI), de Bilt, memorandum VEO 93-01 (in Dutch)

Manuscript first received: July 22, 1996

Revised version accepted: January 7, 1997 